\title{
"As guerras linguísticas": afiliações e rupturas na ciência da linguagem do século XX
}

Ronaldo de Oliveira BATISTA (D)

Universidade Presbiteriana Mackenzie (UPM)

Carlos Henrique Teixeira de ARAÚJO (D)

Universidade Presbiteriana Mackenzie (UPM)

\section{RESUMO}

Por meio de fundamentos teóricos e procedimentos metodológicos da Historiografia da Linguística, Cristina Altman apresenta uma abordagem da história da linguística a partir de um ponto de vista diferenciado: compreender algumas etapas do desenvolvimento de teorias estruturalistas (entre os anos 1920-1950) a partir do contato entre pesquisadores norteamericanos e europeus. Esse contato não se deu de forma pacífica e permite que se observe que a ciência é prática humana, permeada por associações e conflitos. Destacam-se aspectos teóricos e sociais do diálogo entre pesquisadores, envolvidos em comunidades em polarização, com referência também à recepção brasileira diante dos polos opostos que constituíram a assim chamada guerra fria estruturalista.

\section{ABSTRACT}

Through theoretical foundations and methodological procedures of Historiography of Linguistics, Cristina Altman presents an approach to the history of linguistics from a different point of view: understanding some stages of the development of structuralist theories (between the years 1920-1950) from the contact between North American and European researchers. This contact did not take place peacefully and allows us to observe that science is human practice, permeated by associations and conflicts. Theoretical and social aspects of the dialogue between researchers are highlighted, involved 


\section{REVISTA DA ABRALIN}

in polarizing communities, with reference also to the Brazilian reception in front of the opposite poles that constituted the so-called structuralist cold war.

PALAVRAS-CHAVE

Historiografia da Linguística. História da Linguística. Estruturalismo.

\section{KEYWORDS}

Historiography of Linguistics. History of Linguistics. Structuralism.

Professora Titular do Departamento de Linguística da Universidade de São Paulo (USP) e reconhecida como a introdutora do campo da Historiografia da Linguística (HL) no Brasil (entre outras razões, pela publicação de seu livro pioneiro A pesquisa linguística no Brasil: 1968-1988 e pela fundação do Grupo de Trabalho Historiografia da Linguística Brasileira da Anpoll), Cristina Altman apresentou uma conferência do mais alto nível de demonstração do que é e deveria ser uma pesquisa crítica e interpretativa de eventos da história da linguística.

Pesquisadora ativa da HL (desde a década de 1990), ajudou a transmitir em aulas, palestras, conferências, livros, artigos a noção de que a história da linguística e seus eventos são o objeto analítico de um campo que pretende, a partir de fundamentos teórico-metodológicos próprios, interpretar a produção, circulação e recepção de conhecimento sobre a linguagem e as línguas (em qualquer época e em qualquer situação). Esse campo (efetivamente institucionalizado a partir dos anos 1970) é o que se reconhece como Historiografia da Linguística ${ }^{1}$ (ou Historiografia Linguística) ${ }^{2}$.

Em tempos de polarização política, ideológica e social, Altman apresentou um tema atual e relevante para o período em que todos vivemos nesta última década: o embate de ideias; as associações entre pares confrontando duramente o diferente; a busca pelo predomínio de valores próprios a determinados grupos.

Em uma conferência com ares de aula brilhante, Altman recuperou os termos da polarização atual em uma interpretação que destacou como a produção científica em linguística (num recorte temporal entre 1920-1950) pode ser vista criticamente pelo historiógrafo como uma prática científica, mas também humana, uma vez que envolve a formação de grupos de especialidade teórica (cf.

\footnotetext{
1 Na denominação do campo o termo linguística é interpretado em sentido lato, denotando todo e qualquer estudo sobre a linguagem, mesmo aqueles que foram produzidos e circularam, em diferentes formas e modos, antes de um período em que se pode efetivamente falar de uma linguística como ciência, a partir do século XIX.

2 Para uma introdução ao campo da Historiografia da Linguística em textos de língua portuguesa, há: Koerner (2014), Altman (1998), Batista (2013) e a obra coletiva organizada por Batista (org, 2019).
} 


\section{REVISTA DA ABRALIN}

MURRAY, 1994), reunidos por meio dos mais diferentes motivos, inclusive aqueles de natureza geográfica, daí o intrigante título de sua conferência: A Guerra Fria Estruturalista.

A guerra a que Altman faz referência e que serviu de base para sua conferência é o embate teórico-metodológico e social (por conta da busca de vínculos institucionais para pesquisa e ensino) que opôs estruturalistas norte-americanos, em uma filiação que reconhece como líderes intelectuais Edward Sapir (1884-1938) e Leonard Bloomfield (1887-1949), e estruturalistas europeus (situados em Praga e na Rússia), em uma filiação que reconhece como um de seus principais líderes intelectuais Roman Jakobson (1896-1982). A “conexão brasileira” (nos termos de Altman 1999, 2004) dessa oposição se deu por conta das afiliações intelectuais assumidas por Joaquim Mattoso Câmara Jr. (19041970), reconhecido como um dos pioneiros da pesquisa linguística brasileira.

Transmitindo o pressuposto fundamental (e muitas vezes desconhecido ou mesmo ignorado) de que uma história a ser contada deve escapar do impressionismo e se ancorar em fundamentos teóricos e procedimentos metodológicos (resultantes da formação específica do linguista como um historiógrafo de sua área), Altman iniciou sua conferência estabelecendo parâmetros a partir dos quais sua interpretação seria estabelecida. Desse modo, ela definiu, no que chamou de "delimitações", seu ponto de vista: estudar a oposição entre estruturalistas norte-americanos e europeus levando em conta a produção, circulação e recepção do conhecimento sobre a linguagem e as línguas.

Essa delimitação implicou uma periodização que serviu de ponto de partida da sua interpretação historiográfica: 1920-1950, os anos iniciais após o discurso fundador em termos científicos de Ferdinand de Saussure e seu Curso de linguística geral (1916). Delimitou-se a análise nas décadas de 1920 a 1950 para flagrar processos de produção do conhecimento que se deram nesse período e também processos de recepção desse conhecimento. Altman apresentou uma reconstrução dos cenários geográficos para situar o desenvolvimento do estruturalismo nesses espaços (EUA, Europa e Brasil).

Como toda rigorosa investida historiográfica, Altman apresentou os dois parâmetros a guiar sua interpretação: um parâmetro interno, relativo a concepções teóricas sobre língua/linguagem e a seleção de métodos de análise; um parâmetro externo, relativo a aspectos sociais, que permitiram o desenvolvimento de práticas de análise linguística, circunscritas a fatores como institucionalização e reconhecimento de pares. Quatro agentes produtores de conhecimento foram os personagens da narrativa historiográfica de Altman: Sapir, Bloomfield, Jakobson e Mattoso Câmara.

No lado norte-americano da polarização, estava Sapir, que por meio da junção linguística e antropologia, tinha como interesse a análise e descrição dos sons, em trabalho de campo, de línguas indígenas, sem descuidar de um correlato mentalista para sua maneira de entender o funcionamento da linguagem. Ainda nos EUA, em Bloomfield, a visão estruturalista se dava por meio da constituição (com correlato psicológico behaviorista) de uma teoria mecanicista, descartando a mente e suas intenções para focar exclusivamente na localização do objeto de estudo, que seria a parte material das línguas, captada na análise, principalmente, fonética, fonológica e morfológica. Sendo assim, na guerra estruturalista, o lado norte-americano se daria pela busca de métodos de descrição e análise linguística diante de um material peculiar que estava à disposição dos linguistas dos anos 1920-1950: 


\section{REVISTA DA ABRALIN}

as desconhecidas línguas indígenas. Sem dúvida, a base de uma concepção imanente de linguística encontra um dos seus pilares nessa configuração norte-americana de pesquisa linguística.

No lado europeu da polarização, Altman destacou a figura de Jakobson, principalmente por conta da presença desse pesquisador de origem russa na linguística norte-americana no período da $2^{a}$. Guerra Mundial (1939-1945). Esse fator externo, a reorientar a ordem política e geográfica do mundo, contribuiu para a oposição que permitiu a Altman delinear a sua "guerra fria".

Com a chegada de Jakobson e outros europeus aos EUA, a competição por cargos e posições em institutos de ensino e pesquisa evidenciou um confronto direto não só em termos políticos e geográficos, como também em termos teóricos. Jakobson, um dos precursores do funcionalismo, ajudaria a divulgar em centros norte-americanos um estruturalismo mais à europeia, por assim dizer, caracterizado pela interdisciplinaridade com outros campos das ciências humanas. Esse diálogo possibilitou a formação de escolas estruturalistas que recuperariam o estudo do significado, desconsiderado por estruturalistas "duros" (a hard linguistics) na linha de Bloomfield.

Em meio a essa guerra fria entre estruturalistas imanentes e estruturalistas mais abertos ao diálogo interdisciplinar, estava a figura do brasileiro Mattoso Câmara. Importante linguista brasileiro, recebeu apoio financeiro para estudar nos EUA, tendo aulas com representantes da linguística norte-americana mecanicista (conhecida como distribucionalista) e, mais importante, estabelecendo contato próximo com Jakobson (do qual são evidências as correspondências entre eles, cf. Altman, 1999, 2004). A recepção brasileira dessa guerra estruturalista, via Mattoso Câmara, se deixaria pender mais para o estruturalismo à europeia de Jakobson, ainda que o linguista brasileiro tenha regularmente frequentado aulas e lido textos dos estruturalistas norte-americanos.

Essa complexão dimensão geográfica, social, intelectual e científica traçou percursos na história da linguística e foi revisitada em alguns de seus aspectos em uma conferência que só reafirmou o talento e a capacidade ímpar de Altman como historiógrafa da linguística.

Em sua conclusão, Altman ratificou a polarização e as múltiplas possibilidades de interpretação da produção e recepção do conhecimento sobre a linguagem e as línguas quando projetado num eixo histórico que lhe é inevitável, permeado por programas de investigação co-ocorrentes e concorrentes (cf. SWIGGERS, 1981).

Por meio do rigor da análise e da afiada manifestação discursiva que são peculiares a Altman, pôde-se entender a não neutralidade da ciência por conta de fatores da não racionalidade que interferem no percurso da produção, circulação e recepção de ideias linguísticas. Um percurso permeado por afiliações e rupturas que podem ser compreendidas (à luz da sociologia da ciência) pela marcante descrição de John Ziman: "Nunca se trata de um único indivíduo que passa sozinho por todas as etapas da cadeia lógico-indutiva, e sim de um grupo de indivíduos que partilham entre si o trabalho mas fiscalizam permanente e zelosamente as contribuições de cada um. A plateia à qual são endereçadas as publicações científicas não é passiva; por meio de aplausos ou vaias, de flores ou tomates, ela controla eficientemente a substância das comunicações que recebe". Se estruturalistas todos somos em alguma medida, dispersos e opositores também o somos, em grande medida quando buscamos nossas afiliações e legitimações de nossa produção de conhecimento. 


\section{REVISTA DA ABRALIN}

\section{REFERÊNCIAS}

A Guerra Fria Estruturalista. Conferência apresentada por Cristina Altman [s.l., s.n.], 2020.1 vídeo (1h 51min 45s). Publicado pelo canal da Associação Brasileira de Linguística. Disponível em: https://www.youtube.com/watch?v=UsgBMHjwbxU\&t=4251s Acesso em: 12 jun 2020.

ALTMAN, Cristina. A pesquisa linguística no Brasil (1968-1988). São Paulo: Humanitas, 1998.

ALTMAN, Cristina. The 'Brazilian connection'inthe history of North American linguistics: The notebooks of Joaquim Mattoso Câmara (1943-1944). Historiographia Linguistica, v. 26, n.3, p. 355-382, 1999.

ALTMAN, Cristina. A Conexão Americana: Mattoso Câmara e o Círculo Linguístico de Nova Iorque. DELTA, v. 20, p. 129-158, 2004.

BATISTA, Ronaldo de Oliveira. Introdução à Historiografia da Linguística. São Paulo: Cortez, 2013.

BATISTA, Ronaldo de Oliveira (Org.). Historiografia da Linguística. São Paulo: Contexto, 2019.

KOERNER, E.F. Konrad. Quatro décadas de historiografia linguística: estudos selecionados. Sel. e ed. de textos Rolf Kemmler e Cristina Altman. Vila Real: Centro de estudos em letras. Universidade de Trás-os-Montes, 2014.

MURRAY, Stephen O. Theory Groups and the Study of Language in North America: a social history. Amsterdam: John Benjamins, 1994.

SAUSSURE, Ferdiand de. Curso de linguística geral. [Trad. de A. Chelini et al. do orig. em francês]. São Paulo: Cultrix, 1995[1916]. SWIGGERS, Pierre. The History Writing of Linguistics: A Methodological Note. General Linguistics, v. 21, n. 1, p. 11-16, 1981. ZIMAN, John. Conhecimento público. Trad. de R. R. Junqueira do orig. em inglês de 1968. Belo Horizonte: Itatiaia, 1979. 